\title{
PET Scan Investigations of Huntington's Disease: Cerebral Metabolic Correlates of Neurological Features and Functional Decline
}

\author{
Anne B. Young, MD, PhD, John B. Penney, MD, Simon Starosta-Rubinstein, MD, Dorene S. Markel, MS, \\ Stanley Berent, PhD, Bruno Giordani, PhD, Richard Ehrenkaufer, PhD, Douglas Jewett, PhD, \\ and Richard Hichwa, PhD
}

Fifteen drug-free patients with early to midstage Huntington's disease were evaluated with quantitative neurological examinations, scales for functional capacity, computed tomographic (CT) scans, and positron emission tomographic (PET) scans of ${ }^{18}$ F-2-fluoro-2-deoxyglucose $\left({ }^{18}\right.$ F-FDG) uptake. All patients had abnormal indices of caudate metabolism on PET scanning, whereas in patients with early disease indices of putamen metabolism and C'T measures of caudate atrophy were normal. Indices of caudate metabolism correlated highly with the patients' overall functional capacity $(r$ $=0.906 ; p<0.001)$ and bradykinesia/rigidity $(r=-0.692 ; p<0.01)$. Indices of putamen metabolism correlated highly with motor functions: chorea $(r=-0.841 ; p<0.01)$, oculomotor abnormalities $(r=-0.849 ; p<0.01)$, and fine motor coordination $(r=-0.866 ; p<0.01)$. Indices of thalamic metabolism correlated positively with dystonia $(r=$ $0.559 ; p<0.05)$. The data suggest that PET scanning with ${ }^{18} \mathrm{~F}$-FDG is a sensitive measure of brain dysfunction in Huntington's disease and that basal ganglia metabolism is highly correlated with the overall functional capacity of individual patients and with the degree of their motor abnormalities.

Young AB, Penney JB, Starosta-Rubinstein S, Markel DS, Berent S, Giordani B, Ehrenkaufer R, Jewett D, Hichwa R: PET scan investigations of Huntington's disease: cerebral metabolic correlates of neurological features and functional decline. Ann Neurol 20:296-303, 1986

Huntington's disease (HD) is a dominantly inherited neurodegenerative disorder characterized by progressive cognitive and motor deterioration. The clinical features and natural history of the disease have been carefully evaluated and defined. Early neurological signs include chorea, decreased fine motor coordination, and slowed saccadic eye movements $[7,11,16$, 26-29, 35]. Later signs include dysarthria, rigidity, bradykinesia, and dystonia $[7,11,26-28,35]$. With progression, the patient's ability to perform activities of daily living declines [4, 5, 26, 27, 29]. A number of standardized rating scales have been designed to quantify the motor and functional capacities in this disorder $[7,26,27,29,35]$.

Pathologically, HD is characterized by marked neuronal loss in the caudate nucleus and putamen, with coexistent gliosis and astrocytic proliferation $[3$, 15,33 . Little or no cortical abnormality has been observed [33]. The globus pallidus and thalamus are mildly affected as is the cerebellum $[3,6,15]$.

With the advent of positron emission tomographic
(PET) techniques for studying brain metabolism, it has been possible to investigate $\mathrm{HD}$ patients at various stages of their illness to determine the relationship between brain metabolism and the neurological features of the disease [12-14, 23]. Studies with PET have shown a marked reduction of caudate metabolism in patients with early HD who exhibit little or no atrophy as measured by computed tomography (CT) [13]. These earlier studies investigated patients treated with various pharmacological agents and did not attempt to correlate specific neurological and behavioral findings with brain glucose metabolism. We observed 15 unmedicated HD patients who were evaluated carefully by clinical and neuropsychological testing. We present here our findings on the physiological aspects of the illness. Another report on the results of neuropsychological testing is in preparation [2].

\section{Methods}

Fifteen patients with adult-onset HD, as determined by family history and physical examination, were examined at least
From the Departments of Neurology, Psychiatry, Psychology, and Internal Medicine, The University of Michigan, Ann Arbor, MI.

Received Sept 30, 1985, and in revised form Jan 14, 1986. Accepted for publication Jan 20, 1986.
Address reprint requests to Dr Young, The University of Michigan, Neuroscience Lab Bldg, \#1015, 1103 East Huron St, Ann Arbor, MI 48104. 
1 month after discontinuation of any medications. Over a 2day period, patients received: (1) a quantitative neurological evaluation conducted by two or more investigators using a previously designed scale [35]; (2) an evaluation of functional capacity according to the Shoulson and Fahn scale [29]; and (3) neuropsychometric testing (results to be reported separately [2]). In addition, each patient had a CT scan and PET scan using ${ }^{18} \mathrm{~F}$-2-fluoro-2-deoxyglucose $\left({ }^{18} \mathrm{~F}\right.$ FDG).

The $15 \mathrm{HD}$ patients (ages 25 to 60 years; average \pm SEM: $40 \pm 3$ years) were compared with 14 normal controls (ages 25 to 65 years; average \pm SEM: $37 \pm 3$ years). Patients were in stages $\mathrm{I}, \mathrm{II}$, or $\mathrm{III}$ of the disease as defined by the Shoulson and Fahn scale, a total functional capacity (TFC) scale that assesses the patient's ability to be gainfully employed, to handle financial and domestic responsibilities, to perform activities of daily living, and to be cared for at home [29]. It is a 13-point scale with 13 indicating normal and 0 referring to patients who require total care. It is further subdivided into five stages: stage I (TFC 13-11), stage II (TFC 10-7), stage III (TFC 6-3), stage IV (TFC 2-1), and stage V (TFC 0).

For PET studies, patients had an arterial line placed in the radial artery of one arm and an intravenous line in the other arm. ${ }^{18} \mathrm{~F}$-FDG ( 5 to $10 \mathrm{mCi}$ ) was injected as an intraveous bolus while the patient was in a quiet, dimly lit room with minimal background noise, with eyes blindfolded and ears unplugged. Although sensory deprivation is known to affect glucose metabolism in normal subjects [18], these conditions were chosen because they were considered to provide the most reproducible scanning conditions among subjects. Plasma ${ }^{18} \mathrm{~F}$-FDG curves were determined for each patient. Repeated $0.5-\mathrm{ml}$ arterial samples were drawn over the first 45 minutes after injection according to the following protocol: injection to 2 minutes, one sample every 5 seconds, then samples at $3,4,5,6,7,12,17,22,37$, and 45 minutes.

The scans were obtained on a Cyclotron Corporation PET $4600 \mathrm{~A}$ Scanner, which is a three-ring $(2.2-\mathrm{cm}$ center-tocenter spacing), five-slice, 96-detector/ring tomograph. The spatial resolution is $11 \mathrm{~mm}$ in the X-Y plane (within a transaxial slice) and $8.8 \mathrm{~mm}$ in the $Z$ plane (along the central axis of the scanner). Ten transaxial slices separated by approximately $5.5 \mathrm{~mm}$ with an orientation parallel to the canthomeatal line were obtained from the base of the cerebellum to the top of the caudate nucleus. An additional five slices separated by $11 \mathrm{~mm}$ were acquired to image the next $5 \mathrm{~cm}$ of brain. The local glucose metabolic rate (ICMRglc) for each region of brain was calculated according to previously described methods [22, 31] using updated rate constants [Mazziotta JC, personal communication, 1984].

Data from each scan were analyzed by a standard technique as described below. The slice corresponding to the 0 degree Section, No. 8 or No. 9 from the CT atlas of Matsui and Hirano [17], was analyzed in detail from each patient. Cross-sectional histograms through (1) the caudate nucleus (halfway between the rostral edge of the thalamus and the frontal cortex anterior to the ventricles); (2) the putamen (halfway between the caudate cross-section and the rostral edge of the thalamus); and (3) the middle of the thalamus (Fig 1). By inspection of the cross-sectional histograms, the maximum glucose metabolic rate over the head of the cau- date was observed in all the normal controls and in most of the HD parients. Although caudate metabolism in some of the HD patients was quite low, the location of the shoulder on the cross-sectional histogram could be determined by calculating the second derivative of the curve (Fig 2). Although this method of determining caudate metabolism cannot correct for alterations in partial volume, it was found to be more reproducible than values obtained from simple, visually guided region-of-interest (ROI) measurements. This method was also considered to be more accurate than the use of standardized ROI programs, which do not correct for the underlying caudate atrophy in HD. Values of caudate, putamen, and thalamus metabolic activity were taken as an average of data from a $1 \times 3$ pixel ROI $\left(\mathrm{ROI}=\Sigma_{\mathrm{i}}^{3} \Sigma_{\mathrm{j}}^{1} 1 \mathrm{CMRglc} \mathrm{c}_{\mathrm{ij}}\right)$ on a $64 \times 64$ pixel matrix reconstruction of the PET scan data. Raw data from right and left cortex, caudate, putamen, and thalamus were averaged in 10 patients and 10 controls (Table 1). (Data from the first $5 \mathrm{HD}$ patients and first 4 controls were not included in this latter analysis because they were scanned prior to a series of modifications in our scanner that affected absolute but not relative measures of glucose metabolism.) The lack of metabolic change in HD cortex compared with controls suggested that normalization of the values of caudate, putamen, and thalamus to cortex at the same levels was valid for subsequent analyses. Normalization is frequently used in PET studies because it reduces the overall variability of the measures $[13,14,23]$. Absolute measures of metabolism from caudate, putamen, and thalamus were normalized to the peak cortical activity (a $1 \times$ 3 pixel $\left[11 \mathrm{~mm}^{2}\right] \mathrm{ROI}$ ) determined on the same crosssectional histogram (see Fig 1). The normalized values will be referred to as indices of metabolism. The ratio of caudate metabolism to putamen metabolism was also calculated for each patient.

In this study, CT scans were evaluated using previously described techniques $[1,25,30,32]$. Both the frontal horn/ bicaudate diameter ratios (FH/CC) and the bicaudate diameter/outer table diameter ratios (CC/OT) at the level of the caudate were calculated as depicted in Figure 1.

PET and CT scan data were obtained and recorded separately from the clinical information. Data from scans and the clinical evaluations were entered into a computer for analysis. The scan measurements were then compared between the controls and HD patients using $t$ tests. The nonparametric clinical data were analyzed and compared to scan data and to each other using Spearman rank correlation coefficients. Parametric scan data were compared to other scan data using Pearson product-moment correlation coefficients. Data analysis was done using the Biomedical Program Statistical Software (Alphaville, CA).

\section{Results}

All $\mathrm{HD}$ patients had demonstrable PET abnormalities (Figs 2, 3). There were 5 stage I patients, 9 stage II patients, and 1 stage III patient. Measurement of cortical metabolism at the level of the caudate, putamen, and thalamus in the HD patients did not differ significantly from that in controls (see Table 1). In HD patients as a population, the caudate and putamen metabolic activity was significantly decreased compared 


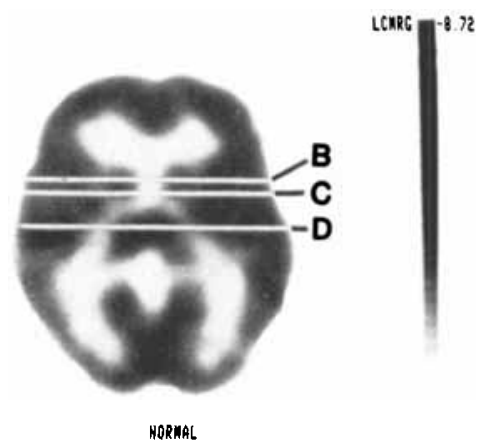

A

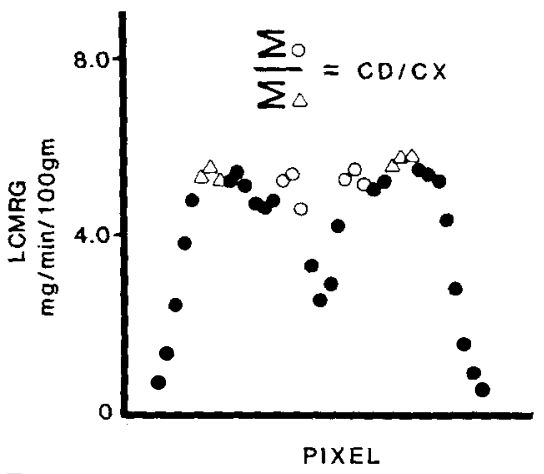

B

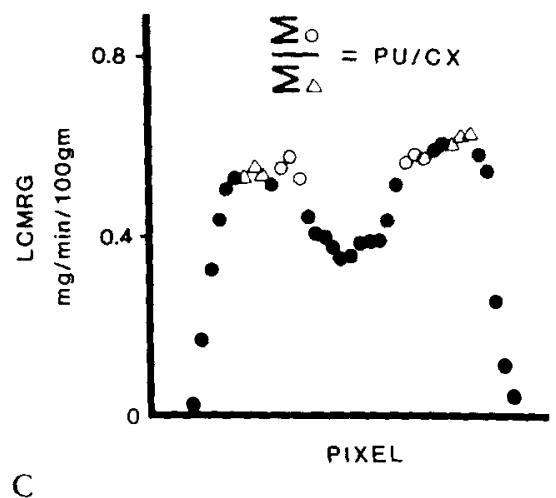

C

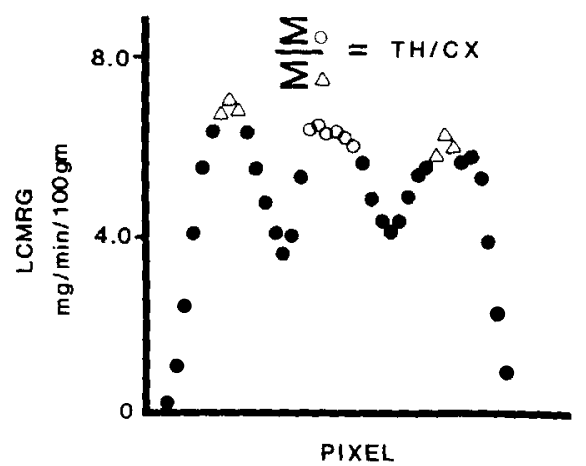

$\mathrm{D}$

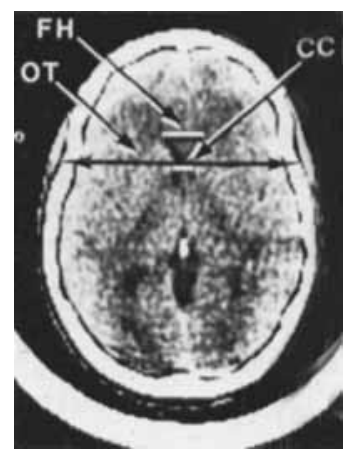

E with controls. The thalamic metabolism in HD patients was not significantly different from control values, but when normalized to cortex as in Figure 1, thalamicl cortex ratios were significantly higher in HD patients than they were in controls $(1.06 \pm 0.14$ standard deviations [SD] versus $0.94 \pm 0.12 \mathrm{SD} ; p<0.02$, Student's independent $t$ test).

Caudate and putamen indices of metabolism were highly correlated with the TFC of the patient (see Fig 3. Table 2). In the earliest stages of the disease, the caudate index in the HD patients fell just below the lowest index of the control group, and as a group, the stage I patients (TFC $=13-11$ ) had significantly lower caudate indices than did the control group $(p<0.01)$. Putamen indices had a strong correlation with TFC, but in stage I patients the putamen indices did not differ significantly from those of the control group. Putamen indices for the stage II patients (TFC $=10-$ 7) were clearly lower than those of controls $(p<0.01)$. The PET measures of caudate and putamen were correlated very highly with each other, but not with the thalamic indices. There was also no correlation between TFC and the thalamic indices of metabolism.

The quantitative neurological measures (chorea, both at rest and during stress), dysdiadochokinesia (evaluated by rapid finger tapping as well as alternating supination and pronation of the hands), abnormalities of saccadic eye movements, bradykinesia/rigidity, and dystonia were analyzed in detail (Table 3). Motor abnormalities were highly correlated with each other, ex-
Fig 1. Summary of positron emission tomographic and computed tomographic (CT) measures. Histograms of cross-sectional metabolic data (A) were obtained through the caudate (B), putamen (C), and thalamus (D). Indices of caudate, putamen, and thalamic metabolism were calculated by determining the peak values of metabolic data through the structures in question (open circles) normalized to the peak cortical activity at the same level (open triangles). (E) CT measures were also made: $\mathrm{CC}=$ the intercaudate distance; $\mathrm{OT}=$ the distance between the outer tables of the skull at the level of the caudate; and FH $=$ the distance between the tips of the frontal borns at the level of the caudate. (LCMRG = local cerebral metabolic rate for glucose $; \mathrm{CD}=$ caudate $; \mathrm{CX}=$ cortex $; \mathrm{PU}=$ putamen $; \mathrm{TH}=$ thalamus.)

Fig 2. Examples of computed tomograpbic (CT) (left) and positron emission tomographic (PET) (middle) scans on a series of cases ranging from normal (A) to stage III Huntington's disease (D). The CT and PET scans were taken at a level midway tbrough the caudate and putamen. To the right of each PET scan is the cross-sectional histogram of metabolic data taken through the caudate (see legend for Figure 1 for method) as shown by the arrows on the PET scans. Note the decrease in caudate metabolism as the disease advances. (LCMRG = local cerebral metabolic rate for glucose; $\mathrm{TFC}=$ total functional $c a-$ pacity, see text for description of staging.) 

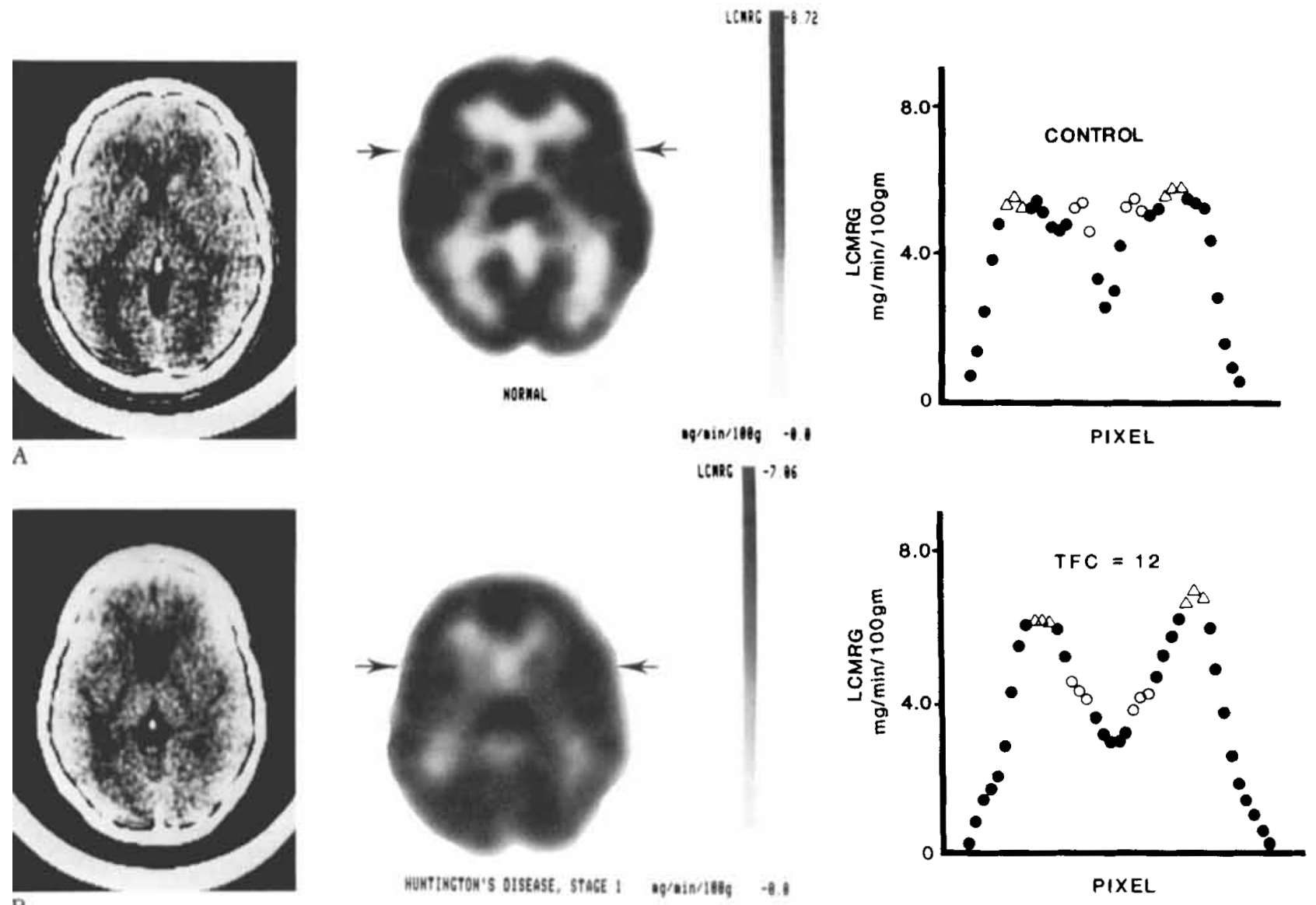

B

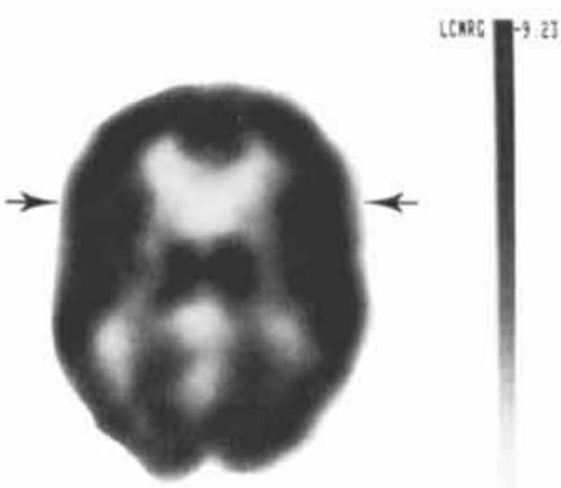

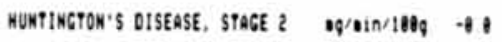
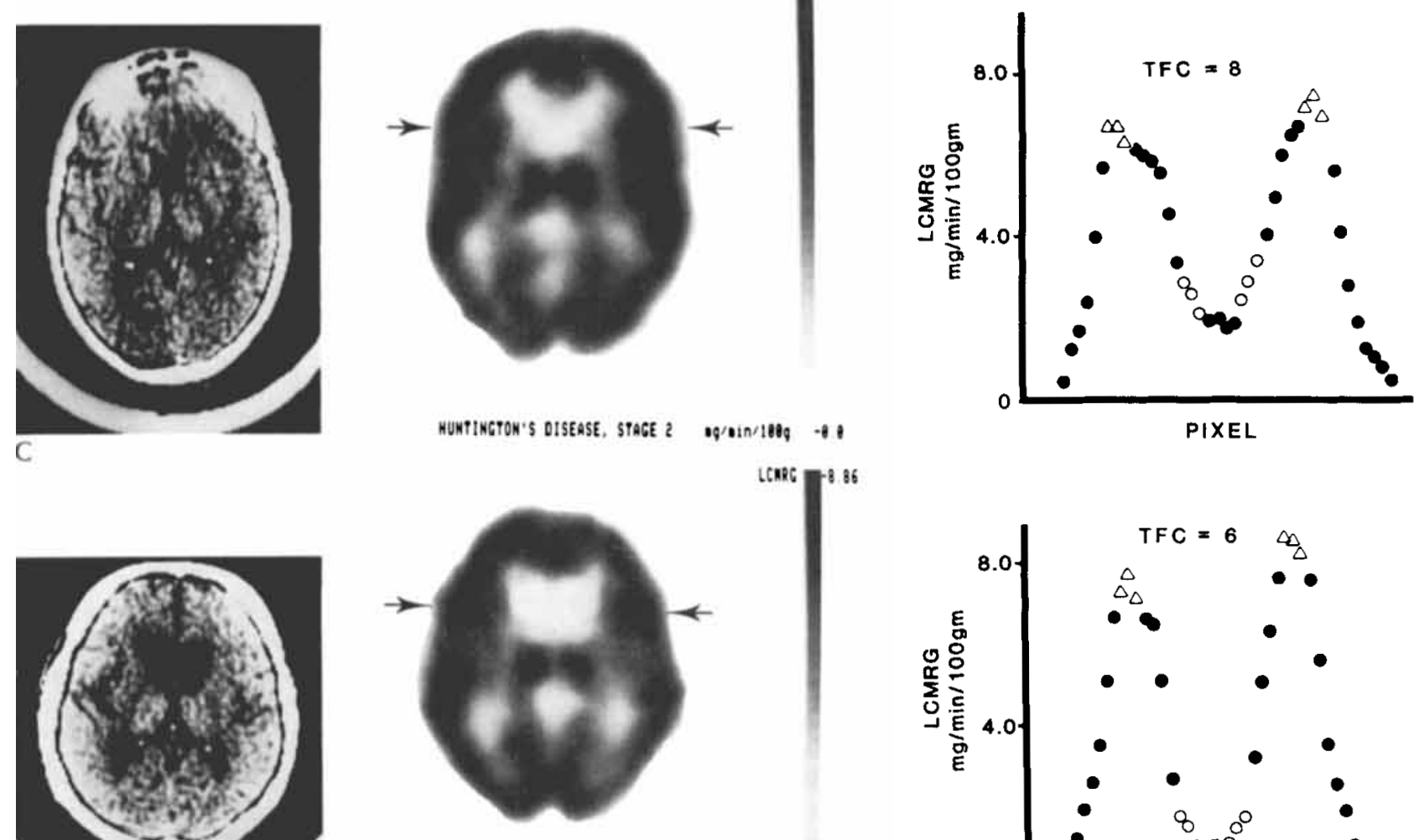

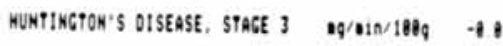

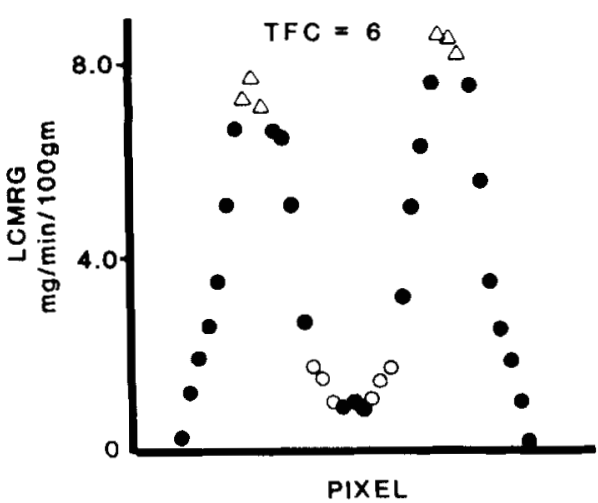


Table 1. Glucose Metabolism in Cortex, Basal Ganglia, and Thalamus of Huntington's Disease Patients and Age-Matched Controls

ICMRglc

$(\mathrm{mg} / \mathrm{min} / 100 \mathrm{gm}$ tissue $\pm \mathrm{SD})$

\begin{tabular}{lll} 
& Controls & $\begin{array}{l}\text { Huntington's } \\
\text { Region }\end{array}$ \\
\hline Cerebral cortex & & \\
At level of caudate & $7.1 \pm 1.8$ & $6.5 \pm 1.5$ \\
At level of putamen & $6.5 \pm 1.8$ & $6.3 \pm 1.4$ \\
At level of thalamus & $6.6 \pm 1.4$ & $6.5 \pm 1.2$ \\
Caudate & $7.1 \pm 1.2$ & $2.8 \pm 1.6^{c}$ \\
Putamen & $7.1 \pm 1.8$ & $3.7 \pm 1.7^{c}$ \\
Thalamus & $6.1 \pm 1.7$ & $7.0 \pm 1.2$ \\
\hline
\end{tabular}

${ }^{a}$ Values are from 10 controls and 10 Huntington's disease patients. bValues from each area represent the raw data obtained from $1 \times 3$ pixel $\left(11 \mathrm{~mm}^{2}\right)$ regions of interest as described in Figure 1.

${ }^{c} p<0.001$ by two-tailed independent Student's $t$ test.

ICMRglc = local cerebral metabolic rate for glucose $; \mathrm{SD}=$ standard deviation.

cept for dystonia which did not relate to abnormal eye movements or bradykinesia/rigidity. Abnormalities on the neurological examination were also highly correlated with alterations in basal ganglia metabolism (see Table 2). Caudate and putamen indices were correlated significantly with TFC and all motor functions except dystonia. Thalamic indices were correlated only with dystonia.

Since PET and CT measures were so highly correlated with each other, multiple linear regression analyses were used to determine the relative contribution of the metabolic and CT data to the functional and neurological features of the patient. The caudate index of metabolism accounted for $85.3 \%$ of the variation in TFC (F $[1,12]=69.6)$, with the $\mathrm{FH} / \mathrm{CC}$ ratio accounting for an additional $4.0 \%$ of the variability $(\mathrm{F}[2,11]=$ 47.6) and the caudate/putamen ratio accounting for another $3.0 \%(F[3,10]=42.1)$. For neurological measures, the putamen index accounted for most of the variability in chorea, dysdiadochokinesia, and abnormal eye movements; the caudate index accounted for the variability of bradykinesia/rigidity; the thalamus and putamen indices together accounted for the variability of dystonia.

CT scan measures of the CC/OT ratio correlated with TFC, oculomotor abnormalities, dysdiadochokinesia, and resting chorea. CC/OT ratios were significantly correlated with PET caudate and putamen indices (Table 4). The $\mathrm{CT}$ scan measure of the $\mathrm{FH} / \mathrm{CC}$ ratio was not significantly correlated with TFC or any of the neurological signs, but was correlated with caudate and thalamic metabolism.

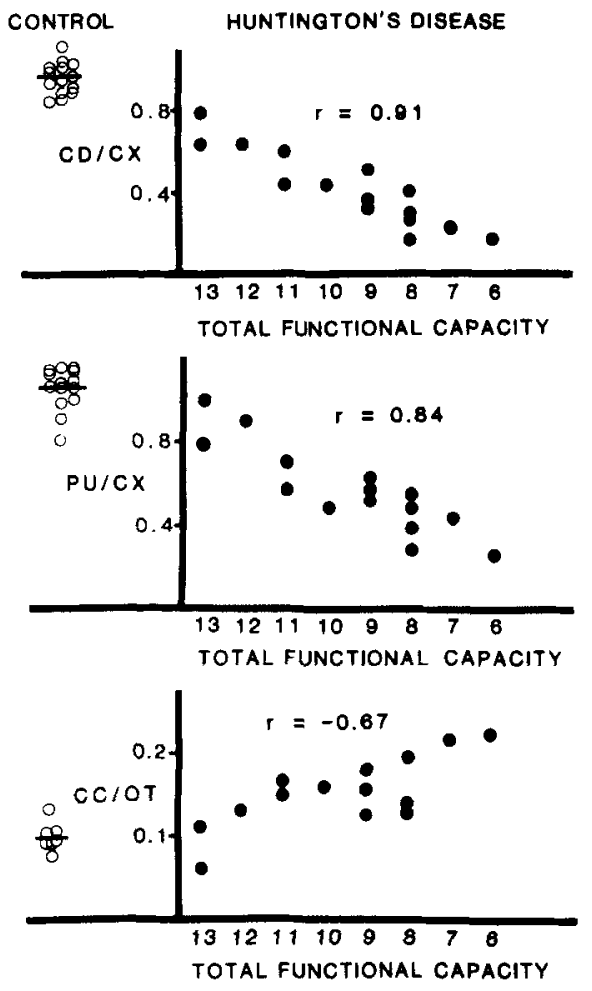

Fig 3. Plots of metabolic and computed tomograpbic (CT) data in a group of controls (open circles) and Huntington's disease (HD) patients (closed circles). There is a bigh degree of correlation between functional capacity and both positron emission tomograpby (PET) and CT measures. PET measures through caudate (top) distinguish the early HD cases more accurately from the controls than do the putamen measures (middle). Numbers indicate the Spearman correlation coefficients $(r)$ of the data.

\section{Discussion}

Our data indicate that basal ganglia metabolism is clearly abnormal in HD and that the degree of metabolic abnormality is correlated both with the patients' overall TFC as well as with their neurological signs and symptoms. The TFC scale used in this study has been validated in prior studies of CT measures [30] and in studies of the clinical progression of the disease [26, $27,35]$. This scale seems to be very sensitive to measures of early progression in the illness. Our study confirms previous CT studies of HD $[25,30,32]$ and provides evidence that metabolic measures in caudate are even more sensitive in early disease than are CT measures. Caudate metabolism is particularly sensitive to functional decline since even patients with the earliest forms of the disease had caudate metabolism below that of the lowest normal subject examined. In these patients with early HD, CT measures were nor$\mathrm{mal}$. The presence of a relationship between functional capacity and caudate metabolism is further established by the strong correlation between TFC and verbal learning and memory, cognitive efficiency, and years 
Table 2. Spearman Rank Correlation Coefficients for the Relationships between Neurological Signs, PET Measures of ICMRglc, and CT Measures of Atropby

\begin{tabular}{|c|c|c|c|c|c|c|}
\hline \multirow[b]{3}{*}{ Clinical Sign } & \multicolumn{4}{|c|}{ PET Measure } & \multirow{2}{*}{\multicolumn{2}{|c|}{ C'T Measure $(n=14)$}} \\
\hline & \multirow[b]{2}{*}{ Caudate } & \multirow[b]{2}{*}{ Putamen } & \multirow{2}{*}{$\begin{array}{l}\text { Caudate/ } \\
\text { Putamen }\end{array}$} & \multirow[b]{2}{*}{ Thalamus } & & \\
\hline & & & & & $\mathrm{CC} / \mathrm{OT}$ & $\mathrm{FH} / \mathrm{CC}$ \\
\hline Total functional capacity $(n=15)$ & $0.906^{c}$ & $0.836^{c}$ & 0.425 & 0.137 & $-0.670^{\mathrm{a}}$ & 0.360 \\
\hline Chorea at rest $(n=15)$ & $-0.761^{\mathrm{c}}$ & $-0.841^{\mathrm{c}}$ & -0.301 & 0.000 & $0.593^{\mathrm{a}}$ & -0.179 \\
\hline Chorea with stress $(n=15)$ & $-0.635^{a}$ & $-0.798^{c}$ & -0.055 & 0.158 & 0.413 & 0.026 \\
\hline Dysdiadochokinesia $(\mathrm{n}=15)$ & $-0.776^{c}$ & $-0.866^{c}$ & -0.248 & -0.011 & $0.676^{\mathrm{b}}$ & -0.339 \\
\hline Slowed saccades $(\mathbf{n}=12)$ & $-0.745^{b}$ & $-0.849^{c}$ & -0.217 & -0.004 & $0.593^{\mathrm{a}}$ & -0.366 \\
\hline Dystonia $(\mathrm{n}=15)$ & -0.235 & -0.497 & 0.062 & $0.559^{\mathrm{a}}$ & 0.204 & -0.305 \\
\hline Bradykinesia/rigidity $(\mathrm{n}=15)$ & $-0.692^{b}$ & $-0.690^{\mathrm{b}}$ & -0.138 & -0.158 & 0.514 & -0.276 \\
\hline Age $(n=15)$ & -0.018 & 0.098 & -0.316 & 0.070 & 0.173 & 0.102 \\
\hline
\end{tabular}

${ }^{\mathrm{a}} p<0.05 ;{ }^{\mathrm{b}} p<0.01 ;{ }^{\mathrm{c}} p<0.002$.

$\mathrm{PET}=$ positron emission tomography $; \mathrm{lCMRglc}=$ local cerebral metabolic rate for glucose $\mathrm{CT}=$ computed tomography; $\mathrm{CC} / \mathrm{OT}=$ bicaudate diameter/outer table diameter ratio; $\mathrm{FH} / \mathrm{CC}=$ frontal horn/bicaudate diameter ratio.

Table 3. Spearman Rank Correlation Coefficients for the Relationships between Various Motor Signs and Total Functional Capacity

\begin{tabular}{|c|c|c|c|c|c|c|}
\hline \multirow[b]{2}{*}{ Motor Signs } & \multicolumn{2}{|c|}{ Chorea } & \multirow[b]{2}{*}{ Dystonia } & \multirow[b]{2}{*}{$\begin{array}{l}\text { Bradykinesia/ } \\
\text { Rigidity }\end{array}$} & \multirow[b]{2}{*}{$\begin{array}{l}\text { Slowed } \\
\text { Saccades }\end{array}$} & \multirow[b]{2}{*}{ Dysdiadochokinesi: } \\
\hline & At Rest & $\begin{array}{l}\text { With } \\
\text { Stress }\end{array}$ & & & & \\
\hline Total functional capacity & $-0.841^{b}$ & $-0.791^{b}$ & -0.444 & $-0.848^{b}$ & $-0.907^{b}$ & $-0.868^{b}$ \\
\hline Chorea at rest & & $0.938^{b}$ & $0.631^{\mathrm{a}}$ & $0.696^{a}$ & $0.714^{\mathrm{a}}$ & $0.805^{b}$ \\
\hline Chorea with stress & & & $0.696^{\mathrm{a}}$ & $0.733^{\mathrm{b}}$ & $0.679^{\mathrm{a}}$ & $0.832^{\mathrm{b}}$ \\
\hline Dystonia & & & & 0.358 & 0.454 & $0.621^{\mathrm{a}}$ \\
\hline Bradykinesia/rigidity & & & & & $0.843^{\mathrm{b}}$ & $0.790^{\mathrm{b}}$ \\
\hline Slowed saccades & & & & & & $0.860^{\mathrm{b}}$ \\
\hline
\end{tabular}

${ }^{a} p<0.05 ;{ }^{b} p<0.002$.

Table 4. Pearson Product-Moment Correlation Coefficients for the Relationships between Various

Positron Emission Tomograpbic and Computed Tomographic Measures

\begin{tabular}{llccr}
\hline Measure & $\begin{array}{l}\text { Putamen } \\
\text { Metabolism }\end{array}$ & $\begin{array}{c}\text { Thalamus } \\
\text { Metabolism }\end{array}$ & CC/OT & FH/CC \\
\hline Caudate metabolism & $0.786^{\mathrm{b}}$ & 0.373 & $-0.863^{\mathrm{b}}$ & $0.656^{\mathrm{a}}$ \\
Putamen metabolism & & -0.018 & $-0.660^{\mathrm{a}}$ & 0.378 \\
Thalamus metabolism & & & -0.436 & $0.640^{\mathrm{a}}$ \\
CC/OTcc & & & & $-0.817^{\mathrm{b}}$ \\
\hline
\end{tabular}

$a_{p}<0.05$.

$\mathrm{s} p<0.002$.

CC/OT $=$ bicaudate diameter/outer table diameter ratio correlation coefficient; $\mathrm{FH} / \mathrm{CC}=$ frontal horn/bicaudate diameter ratio.

after diagnosis. Also, there is a strong correlation between caudate metabolism and learning and memory [2].

The fact that in early HD caudate metabolism is affected more dramatically than is putamen metabolism reinforces the pathological information on patients with early disease that the disorder begins in the caudate nucleus (specifically the dorsal medial areas of caudate) and then progresses to the putamen [33].
Putamen metabolism is not as sensitive since there was overlap between stage I patients and the control group in this measure. That caudate and putamen metabolism were only mildly reduced in patients with early disease suggests that either the symptoms of HD begin soon after the onset of neuronal damage or that compensatory properties maintain or even increase metabolic activity in the remaining basal ganglia neurons.

Caudate metabolism was not as significantly cor- 
related with motor abnormalities as was putamen metabolism. However, caudate metabolism was correlated very highly with putamen metabolism $(r=$ $+0.786 ; p<0.002$ ), and so the relative contributions of each are difficult to discern. Since the caudate nucleus receives its major inputs from association cortex and not from primary motor and sensory cortex [8], the lower correlations of caudate metabolism with motor variables are noteworthy. Thus, decreased caudate metabolism would likely reflect primarily impairment of cognitive and integrative functions and be less indicative of pure motor dysfunction. The high correlation of caudate indices of metabolism with TFC suggests that the cognitive dysfunction in $\mathrm{HD}$ influences TFC to a major extent. The disturbance in cognition may subserve a lowering of TFC. New learning correlated highly with both TFC and caudate metabolism [2]. However, there was a lack of correlation between cognitive and motor measurements [2]. Furthermore, multiple linear regression analyses suggest that caudate metabolism was the most important feature in determining TFC.

The high correlation of putamen metabolism with motor abnormalities may reflect the fact that the putamen receives input from sensory and motor cortex [8]. Multiple regression analyses further support this conclusion since putamen indices explained most of the variability in the motor features except for dystonia and bradykinesia/rigidity. Thus, dysfunction of putamen neurons would likely lead to poor motor coordination.

Thalamic activity was correlated with dystonia, and it is of interest that metabolic activity in this area was increased in the HD patients as a group compared with controls. Neuroanatomical and neurochemical information suggests that the caudate and putamen output cells project to the medial and lateral globus pallidus and substantia nigra pars reticulata [8]. These projections are primarily inhibitory and $\gamma$-aminobutyric acid-ergic (GABAergic) [20, 34]. The medial globus pallidus and substantia nigra pars reticulata neurons are also inhibitory and GABAergic, and project to the thalamus $[20,34]$. Thus the increased thalamic metabolism in HD patients may represent a disinhibition of pallidothalamic and nigrothalamic pathways. Our data would suggest that excessive input to the thalamus from the globus pallidus and substantia nigra pars reticulata may contribute to dystonic motor abnormalities. We plan a future study of rigid and dystonic juvenile patients.

There have been other studies of PET scanning in HD [12-14, 19, 21, 23]. As previously described, we found a significant decrease in the glucose metabolic rate in the basal ganglia of patients with early disease while there was little or no caudate atrophy observed on CT scans. However, unlike previous authors [12, 14 ], we found less difference between the glucose metabolic rate of our patients with early disease and that of controls. In addition, we observed strong direct correlations between metabolic indices and the degree of functional or motor abnormalities in the patients. Others have studied at-risk persons and found altered metabolism in about one half of the subjects $[12,13]$. Some of these patients have gone on to develop HD [12]. We are currently studying 40 at-risk persons prospectively but have found only minimal caudate changes to date. The studies in at-risk persons will help define further the relationship between the earliest metabolic changes and motor and cognitive decline.

In summary, PET measures of basal ganglia metabolism have reinforced our knowledge of basal ganglia anatomy, physiology, and pathology and suggest that such measures will be useful indicators of functional and clinical decline in HD patients. If subsequent atrisk studies confirm that there are significant metabolic changes before the onset of symptoms, then prophylactic therapy in conjunction with PET scanning may provide a useful measure of therapeutic agents. Such measures will be particularly important since the new data describing a DNA marker linked to the HD gene will soon allow the diagnosis of $\mathrm{HD}$ in presymptomatic patients [9, 10].

\section{Supported by USPHS Grant NS 15655.}

We thank Jill Rothley and Annette Betley for helping administer the scans, Roger Lininger and William Downer for operating the cyclotron, Jan Potocki and Carla Caretto for synthesizing ${ }^{18} \mathrm{~F}-\mathrm{FDG}$, and Kent Gardner, Michael Schork, and Judith Bromberg for help in data analysis and statistics. We also thank Michaela Weeks and Jan Pappas for secretarial assistance.

\section{References}

1. Barr AN, Heinze WJ, Dobben GD, et al: Bicaudate index in computerized tomography of Huntington's disease and cerebral atrophy. Neurology (NY) 28:1196-1200, 1978

2. Berent $S$, Giordani $B$, Young $A B$, et al: Positron emission tomography (PET) of ${ }^{18} \mathrm{~F}$-2-fluoro-2-deoxy-D-glucose ( ${ }^{18} \mathrm{FDG}$ ) uptake in the area of the caudate nucleus of patients with Huntington's disease: findings with the Wechsler Memory Scale. International Neuropsychological Society Bulletin, November, 1984, p 5

3. Bruyn GW: Huntington's chorea: historical, clinical and laboratory synopsis. In Vinken P, Bruyn GW (eds): Handbook of Clinical Neurology, Vol. 6. Amsterdam, Elsevier, 1968, pp 298-378

4. Butters N, Albert MS, Sax DS: Investigations of the memory disorders of patients with Huntington's disease. In Chase TN, Wexler NS, Barbeau A (eds): Advances in Neurology, Vol. 23. New York, Raven, 1979, pp 203-213

5. Butters N, Sax D, Montgomery K, Tarlow S: Comparison of the neuropsychological deficits associated with early and advanced Huntington's disease. Arch Neurol 35:585-589, 1978 
6. Dom R, Malfroid M, Baro F: Neuropathology of Huntington's chorea: studies of the ventrobasal complex of the thalamus. Neurology (Minneap) 26:64-68, 1976

7. Folstein SE, Jensen B, Leigh RJ, Folstein MF: The measurement of abnormal movement: methods developed for Huntington's disease. Neurobehav Toxicol Teratol 5:605-609, 1983

8. Graybiel AM: Neurochemically specified subsystems in basal ganglia. In Evered D, O'Connor M (eds): Functions of the Basal Ganglia. London, Pitman, 1984, pp 114-149

9. Gusella JF, Tanzi RE, Anderson MA, et al: DNA markers for nervous system diseases. Science 225:1320-1326, 1984

10. Guselia JF, Wexler NS, Conneally PM, et al: A polymorphic DNA marker genetically linked to Huntington's disease. $\mathrm{Na}$ ture 306:234-238, 1983

11. Hayden M: Huntington's Chorea. Berlin, Springer-Verlag, 1981

12. Kuhl DE, Markham CH, Metter EJ, et al: Local cerebral glucose utilization in symptomatic and presymptomatic Huntington's disease. In Sokoloff $\mathrm{L}$ (ed): Brain Imaging and Brain Functions. New York, Raven, pp 199-210, 1985

13. Kuhl DE, Metter EJ, Riege WH, Markham CH: Patterns of cerebral glucose utilization in Parkinson's disease and Huntington's disease. Ann Neurol 15:S1 19-S125, 1984

14. Kuhl DE, Phelps ME, Markham CH, et al: Cerebral metabolism and atrophy in Huntington's disease determined by ${ }^{18} \mathrm{FDG}$ and computed tomographic scan. Ann Neurol 12:425-434, 1982

15. Lange HW: Quantitative changes of telencephalon, diencephalon and mesencephalon in Huntington's chorea, postenceph alitic and idiopathic parkinsonism. Verh Anat Ges 75:923-925, 1981

16. Martin JB: Huntington's disease: new approaches to an oid problem. Neurology (Cleveland) 34:1059-1072, 1984

17. Matsui T, Hirano A: An Atlas of the Human Brain for Com puterized Tomography. Tokyo, Igaku-Shoin, 1978

18. Mazziotta JC, Phelps ME, Carson RE, Kuhl DE: Tomographic mapping of cerebral metabolism: sensory deprivation. Ann Neurol 12:435-444, 1982

19. Mazziotta JC, Wapenski J, Phelps ME: Cerebral metabolic responses to complex motor tasks: normal subjects versus patients with Huntington's disease. Soc Neurosci Abstr 10:523, 1984

20. Penney JB, Young AB: Speculations on the functional anatomy of basal ganglia disorders. Annu Rev Neurosci 6:73-94, 1983

21. Penney JB, Young AB, Berent S, et al: Positron emission to- mographic (PET) scanning in Huntington's disease: studies of ${ }^{18} \mathrm{~F}$-2-fluoro-2-deoxy-D-glucose $\left[{ }^{18} \mathrm{~F}\right.$-FDG] uptake in 12 drugfree cases. Soc Neurosci Abstracts 10:994, 1984

22. Phelps ME, Huang SC, Hoffman EJ, et al: Tomographic measurement of local cerebral glucose metabolic rate in humans with (F-18)2-fluoro-2-deoxy-D-glucose: validation of method. Ann Neurol 6:371-388, 1979

23. Phelps ME, Mazziotta JC: Positron emission tomography: human brain function and biochemistry. Science 228:799-809, 1985

24. Sanberg PR, Coyle JT: Scientific approaches to Huntington's disease. CRC Crit Rev Clin Neurobiol 1:1-44, 1984

25. Sax DS, O'Donnell B, Butters $N$, et al: Computed tomographic, neurologic, and neuropsychological correlates of Huntington's disease. Int J Neurosci 18:21-36, 1983

26. Shoulson I: Huntington's disease: functional capacities in patients treated with neuroleptic and antidepressant drugs. Neurology (NY) 31:1333-1335, 1981

27. Shoulson I: Care of patients and families with Huntington's disease. In Marsden CD, Fahn S (eds): Movement Disorders (International Medical Review Series). London, Butterworth Scientific, 1982, pp 277-290

28. Shoulson I: Huntington's disease: a decade of progress. Neurol Clin 2:515-526, 1984

29. Shoulson I, Fahn S: Huntington disease: clinical care and evaluation. Neurology (NY) 29:1-3, 1979

30. Shoulson I, Plassche W, Odoroff C: Huntington's disease: caudate atrophy parallels functional impairment. Neurology (NY) 32(suppl I):A143, 1982

31. Sokoloff L: The relationship between function and energy metabolism: its use in the localization of functional activity in the nervous system. Neurosci Res Program Bull 19:159-210, 1981

32. Stober T, Mussow W, Schimrigk K: Bicaudate diameter-the most specific and simple CT parameter in the diagnosis of Huntington's disease. Neuroradiology 26:25-28, 1984

33. Von Sattel JP, Ferrante RJ, Stevens TJ, et al: Neuropathologic classification of Huntington's disease. J Neuropathol Exp Neurol 44:559-577, 1985

34. Young AB, Penney JB: Neurochemical anatomy of movement disorders. Neurol Clin 2:417-433, 1984

35. Young AB, Shoulson I, Penney JB, et al: Huntington's disease in Venezuela: neurological features and functional decline. Neurology (Cleveland) 36:244-249, 1986 